(c) American Dairy Science Association, 2006.

\title{
Effect of Interval from Timed Artificial Insemination to Initiation of Resynchronization of Ovulation on Fertility of Lactating Dairy Cows
}

\author{
R. A. Sterry, ${ }^{\star}$ M. L. Welle, $†$ and P. M. Fricke*1 \\ *Department of Dairy Science, University of Wisconsin, Madison 53706 \\ †Miltrim Farms, Inc., Athens, WI 54411
}

\begin{abstract}
To compare 2 strategies for systematically resynchronizing ovulation, lactating Holstein cows $(\mathrm{n}=763)$ at various days in milk and prior artificial insemination services were assigned randomly at timed AI (TAI) to receive the first GnRH injection of Ovsynch 26 (D26) or 33 (D33) d after TAI to resynchronize ovulation (Resynch) in cows failing to conceive. Cows in the D26 treatment received GnRH $26 \mathrm{~d}$ after TAI and continued Resynch only when diagnosed not pregnant by using ultrasonography $33 \mathrm{~d}$ after TAI, whereas D33 cows initiated Resynch only when diagnosed not pregnant 33 $\mathrm{d}$ after TAI. Cows were classified based on the presence or absence of a corpus luteum (CL) at the not-pregnant diagnosis, and cows without a CL received an intravaginal progesterone-releasing insert during Resynch. When analyzed as a systematic strategy, pregnancy rate per $\mathrm{AI}(\mathrm{PR} / \mathrm{AI})$ was greater for cows assigned to the D33 than the D26 Resynch treatment (39.4 vs. $28.6 \%)$. A treatment $\times$ parity interaction was detected for PR/AI after Resynch for nonpregnant cows having a CL in which primiparous cows had a greater PR/AI than multiparous cows when Resynch was initiated 33 $\mathrm{d}$ after the initial TAI, and primiparous and multiparous cows when Resynch was initiated $26 \mathrm{~d}$ after the initial TAI. Pregnancy loss for Resynch was $6.4 \%$ between 33 and $40 \mathrm{~d}$, and $2.6 \%$ between 40 and $61 \mathrm{~d}$ after Resynch TAI. We concluded that delaying initiation of Resynch until $33 \mathrm{~d}$ after TAI increased PR/AI for primiparous cows.
\end{abstract}

Key words: dairy cow, Ovsynch, pregnancy loss, Resynch

\section{INTRODUCTION}

Because shortened duration and decreased expression of estrus in high-producing dairy cows present a challenge for detection of estrus (Lopez et al., 2004b),

Received September 2, 2005.

Accepted December 28, 2005.

${ }^{1}$ Corresponding author: pmfricke@wisc.edu hormonal protocols that diminish reliance on detection have become popular tools for reproductive management. Programs such as Ovsynch (synchronization regimen using sequential injections of $\mathrm{GnRH}$ and $\mathrm{PGF}_{2 \alpha}$ to control ovulation for timed insemination; Pursley et al., 1995) or Presynch (post partum regimen using 2 injections of $\mathrm{PGF}_{2 \alpha}$ to synchronize estrous cycles in cows before applying Ovsynch) + Ovsynch (Moreira et al., 2001; Navanukraw et al., 2004) systematically program cows to receive their first postpartum timed AI (TAI) without the need for detection of estrus. Strategies that allow hormonal injections, TAI, and pregnancy diagnosis to be scheduled on the same days each week make synchronization protocols easier to manage and may facilitate protocol compliance (Fricke et al., 2003).

For maximum reproductive efficiency, cows failing to conceive to their first postpartum TAI need to be identified and aggressively resubmitted for subsequent AI service (Fricke, 2002). An optimal resynchronization program would provide an opportunity for cows diagnosed not pregnant to receive a subsequent TAI as soon as possible after diagnosis while still achieving acceptable fertility. To this end, a field trial was conducted to determine differences in fertility after initiating Ovsynch for second TAI service (Resynch) at 19 (D19), 26 (D26), or 33 (D33) d after first postpartum TAI for cows submitted to a Presynch + Ovsynch protocol (Fricke et al., 2003). These intervals were selected because they allowed the first GnRH injection of Resynch to be administered exactly 4, 5, or 6 wk after the first GnRH injection of Ovsynch for first postpartum TAI, thereby restricting injections to $2 \mathrm{~d}$ per week on the farm. Initiation of Resynch $19 \mathrm{~d}$ after TAI resulted in a reduced pregnancy rate per AI (PR/AI) compared with initiation of Resynch 26 or $33 \mathrm{~d}$ after TAI, and was not considered an acceptable protocol. Although PR/AI of cows in the D26 and D33 treatments was similar (34 vs. 38\%, respectively), pregnancy diagnosis was conducted at $26 \mathrm{~d}$ after TAI for D26 cows and at $33 \mathrm{~d}$ after TAI for the D33 cows, thus confounding a direct comparison of PR/AI between these treatments.

Initiation of Ovsynch on $\mathrm{d} 5$ to 12 of the estrous cycle resulted in a greater PR/AI compared with initiation 
at other stages of the cycle (Vasconcelos et al., 1999; Moreira et al., 2000). To optimize fertility to Resynch TAI, Bartolome et al. (2005) assigned cows to protocols for resynchronization according to stage of the estrous cycle based on ultrasound and palpation $30 \mathrm{~d}$ after AI. An alternative approach is to time initiation of Resynch at an interval after initial TAI when a high proportion of cows would be expected to be $\mathrm{d} 5$ to 12 of the estrous cycle similar to that achieved using Presynch + Ovsynch. Because PR/AI to Resynch was poor for cows without a corpus luteum (CL) at the first $\mathrm{GnRH}$ or $\mathrm{PGF}_{2 \alpha}$ injections of Resynch (Fricke et al., 2003), alternative treatments aimed at improving fertility of cows lacking a CL at initiation of Resynch may further improve an overall resynchronization strategy.

The overall objective of this study was to compare 2 strategies for systematic resynchronization of ovulation in lactating dairy cows. Our first objective was to evaluate PR/AI for cows in which the first GnRH injection of Resynch was initiated either 26 or $33 \mathrm{~d}$ after an initial TAI. Within each Resynch treatment, cows lacking a CL at a not-pregnant diagnosis were identified and treated with progesterone (using a controlled internal drug-releasing insert, CIDR) during Resynch with the intent of improving fertility to the overall Resynch strategy. A second objective was to determine rate of pregnancy loss at specific intervals after TAI for both the previous TAI and the Resynch treatment TAI to determine the timing of not-pregnant diagnosis during Resynch. Based on our previous results (Fricke et al., 2003), our hypothesis was that initiation of Resynch 33 $\mathrm{d}$ after the previous TAI would yield greater PR/AI to TAI compared with initiation of Resynch $26 \mathrm{~d}$ after the previous TAI.

\section{MATERIALS AND METHODS}

\section{Farm Description and Data Collection}

Lactating Holstein dairy cows on a commercial dairy farm comprising approximately 1,100 lactating cows located in north-central Wisconsin were enrolled in this study beginning July 15, 2004 and ending November 4,2004 . Cows were housed in freestall barns and were fed a TMR once daily with ad libitum access to feed and water. Cows were milked thrice daily at approximately 8-h intervals, and average milk production per cow was $40.0 \pm 0.5 \mathrm{~kg} / \mathrm{d}$ during the study period. Hormonal protocols to synchronize ovulation for first TAI service and to resynchronize ovulation for second and greater TAI services was performed using intramuscular injections of $100 \mu \mathrm{g}$ of $\mathrm{GnRH}$ ( $2 \mathrm{~mL}$ of Cystorelin, Merial, Ltd., Duluth, GA), and $25 \mathrm{mg}$ of $\mathrm{PGF}_{2 \alpha}(5 \mathrm{~mL}$ of Prostamate; Am Tech Group Inc., St. Joseph, MO).
Lists for scheduled injections and pregnancy examinations for individual cows were generated weekly using a commercial on-farm computer software program (Dairy Comp 305, Valley Agricultural Software, Tulare, CA). This program also was used to track and record reproductive outcomes, individual cow events, and monthly milk production records. Cows assigned to the study were identified and coded by treatment on each cow's individual electronic cow card, and the cow file chronicling events for each cow was archived at least once monthly to capture individual cow data throughout the study period. Data from archived cow files were exported into a computer spreadsheet program (Microsoft Excel 2002, Microsoft Corporation, Redmond, WA) for organization and manipulation of data before statistical analysis.

\section{Submission of Cows for Al Service}

Lactating cows ( $\mathrm{n}=763$ ) were allocated weekly to breeding groups, each of which included cows that had calved during the same week, but had not yet been inseminated and cows that had received a previous AI, but were diagnosed not pregnant. In this way, cows were managed in groups to receive hormone injections and TAI on 2 preselected days of the week (Tuesdays and Thursdays). Protocol for insemination, lactation number, DIM, and AI number are shown in Table 1.

At the onset of the trial, any cow receiving TAI or an AI to a detected estrus on a Thursday was eligible to be enrolled into study and randomized to 1 of the 2 treatments. Cows receiving an AI breeding that were diagnosed not pregnant at the weekly herd check then continued the resynchronization schedule based on the treatment to which they were randomized. Thus, several different methods for submitting cows to the AI previous to the TAI of the Resynch treatments were possible. Cows received their first postpartum TAI at $69 \pm 3$ DIM after Presynch $\left(\mathrm{n}=293 ; \mathrm{PGF}_{2 \alpha}\right.$ at $32 \pm 3$ and $46 \pm 3$ DIM) followed by Ovsynch $(\mathrm{GnRH}, \mathrm{d} 0$; $\mathrm{PGF}_{2 \alpha}, \mathrm{d} 7 ; \mathrm{GnRH}+$ timed AI, d 9) initiated $14 \mathrm{~d}$ after the second Presynch injection. As part of the farm's standard reproductive management protocol for treatment of anovular cows, all cows were submitted to ultrasound at the first GnRH injection of Presynch + Ovsynch, and cows lacking a CL $\geq 10 \mathrm{~mm}$ received a modified protocol that included treatment with progesterone (Presynch + CIDR, $\mathrm{n}=88 ; \mathrm{GnRH}$ and CIDR inserted, d $0 ; \mathrm{PGF}_{2 \alpha}$ and CIDR out, d 7; GnRH + timed AI, d 9). For second or greater TAI, cows received Resynch starting on d 26 (D26 and D26 + CIDR) or d 33 (D33 and D33 + CIDR; Figure 1). In addition, cows not examined at scheduled pregnancy diagnosis at $33 \mathrm{~d}$, but subsequently diagnosed not pregnant (extended interval; 
Table 1. Characteristics of and reproductive outcomes for lactating Holstein cows receiving AI immediately preceding the Resynch TAI treatments

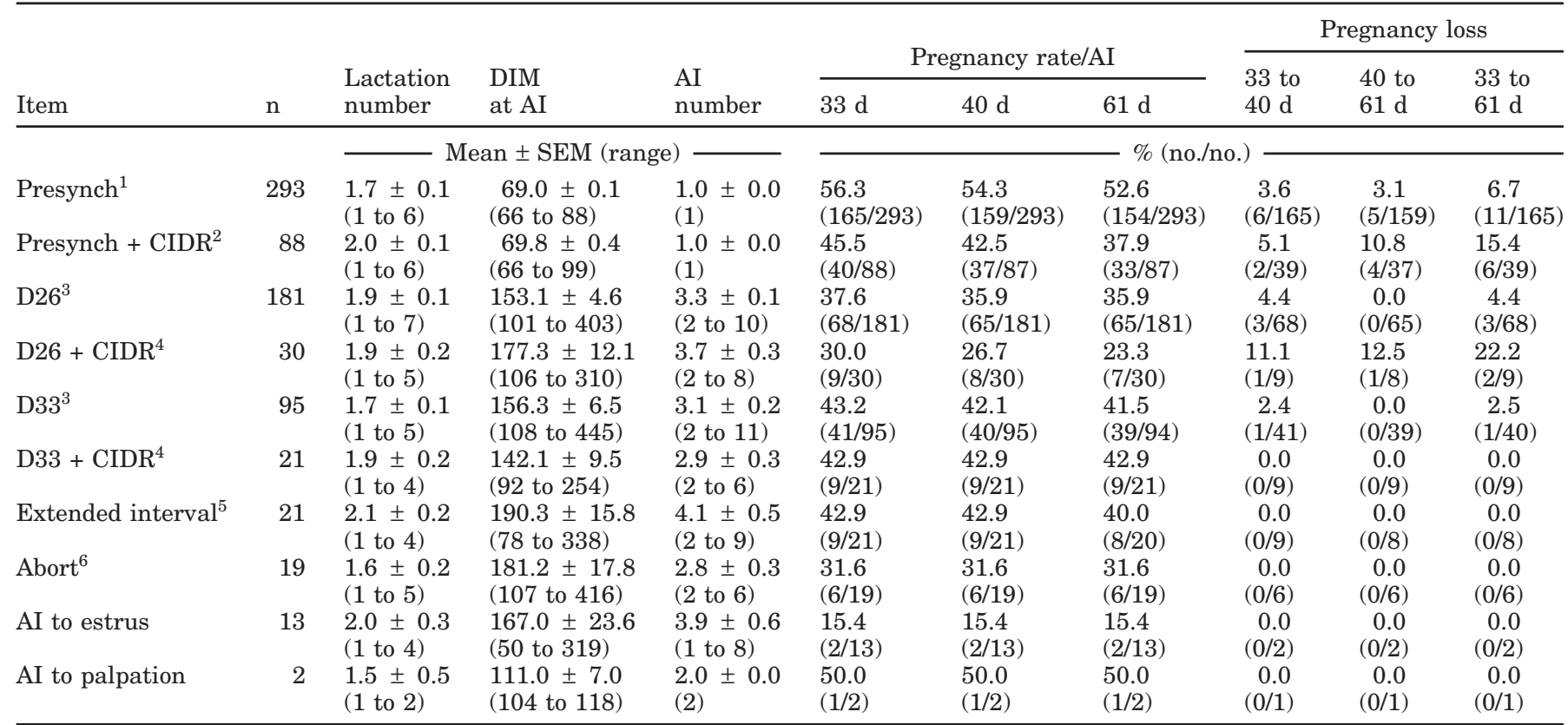

${ }^{1}$ Cows received their first postpartum timed AI at $69 \pm 3$ DIM in response to Presynch ( $\mathrm{PGF}_{2 \alpha} 32 \pm 3$ and $46 \pm 3$ DIM) followed by Ovsynch (GnRH, d 0; $\mathrm{PGF}_{2 \alpha}$, d 7; GnRH + timed AI, d 9), initiated $14 \mathrm{~d}$ after the second Presynch injection.

${ }^{2}$ Cows received their first postpartum timed AI at $69 \pm 3$ DIM in response to Presynch $\left(\mathrm{PGF}_{2 \alpha} 32 \pm 3\right.$ and $46 \pm 3$ DIM) followed by Ovsynch (GnRH and CIDR inserted, d 0; PGF ${ }_{2 \alpha}$ and CIDR out, $d$ 7; GnRH + timed AI, d 9), initiated $14 \mathrm{~d}$ after the second Presynch injection. Only cows lacking a CL at the first GnRH of Ovsynch received a CIDR.

${ }^{3}$ Cows received their second or greater timed AI (i.e., Resynch) after initiating Ovsynch $\left(\mathrm{GnRH}, \mathrm{d}\right.$ 0; $\mathrm{PGF}{ }_{2 \alpha}$, d 7; GnRH + timed AI, d 9) 26 or $33 \mathrm{~d}$ after a previous TAI.

${ }^{4}$ Cows received their first GnRH injection $26 \mathrm{~d}$ (D26 + CIDR) after previous TAI, and lacked a CL $7 \mathrm{~d}$ later at the not-pregnant diagnosis, or received no GnRH injection prior to not-pregnant diagnosis and lacked a CL (D33 + CIDR). These cows received Ovsynch (GnRH and CIDR in, d 0; $\mathrm{PGF}_{2 \alpha}$ and CIDR out, d 7; GnRH + timed AI, d 9) 26 or $33 \mathrm{~d}$ after previous TAI.

${ }^{5}$ Cows receiving their second or greater timed AI (i.e., Resynch) after initiating Ovsynch (GnRH, d 0; PGF $2 \alpha, d$ 7; GnRH + timed AI, d 9) $40 \mathrm{~d}$ or greater after a previous TAI.

${ }^{6}$ Cows receiving their second or greater timed AI (i.e., Resynch) after initiating Ovsynch $\left(\mathrm{GnRH}, \mathrm{d}\right.$ 0; $\mathrm{PGF} \mathrm{F}_{2 \alpha}, \mathrm{d}$ 7; GnRH + timed AI, d 9) after being diagnosed pregnant, and subsequently diagnosed not pregnant.

$\mathrm{n}=21$ ), or diagnosed not pregnant after previously being diagnosed as pregnant (abort; $\mathrm{n}=13$ ) were assigned to Resynch at the not-pregnant diagnosis. Fifteen cows did not receive a TAI before Resynch and were inseminated to detected estrus (AI to estrus; $n=$ 13 ) or based on a rectal palpation (AI to palpation; $\mathrm{n}=2$ ).

\section{Submission of Cows to Resynch Treatments}

After the previous AI, cows were assigned randomly to either of 2 Resynch treatments for resynchronization of ovulation using Ovsynch. Insemination was conducted concurrent to the second GnRH injection of Ovsynch [Cosynch; $100 \mu \mathrm{g}$ of $\mathrm{GnRH}(\mathrm{d}-9), 25 \mathrm{mg}$ of $\mathrm{PGF}_{2 \alpha}(\mathrm{d}-2)$, and $100 \mu \mathrm{g}$ of GnRH + TAI (d 0)] for cows failing to conceive to the previous AI. Nonpregnant cows assigned to a Resynch treatment after the Resynch TAI were rerandomized to treatments for second or greater Resynch TAI.

Because previous results demonstrated that cows having a CL $\geq 10 \mathrm{~mm}$ in diameter had greater PR/AI than cows without a $\mathrm{CL}>10 \mathrm{~mm}$ at the not-pregnant diagnosis (Fricke et al., 2003), cows in this study were classified at the not-pregnant diagnosis as either having or lacking a $\mathrm{CL} \geq 10 \mathrm{~mm}$ in diameter by using an ultrasound machine equipped with a transrectal $5.0-\mathrm{MHz}$ linear-array transducer (Aloka 500V; Corometrics Medical Systems, Inc., Wallingford, CT). Briefly, both ovaries were visualized and presence or absence of a CL $\geq 10 \mathrm{~mm}$ in diameter was recorded. This classification method was used because it allowed for rapid and accurate evaluation of CL diameter using the $10-\mathrm{mm}$ hash marks on the ultrasound screen without repeated freezing of the ultrasound image (Fricke et al., 2003). 


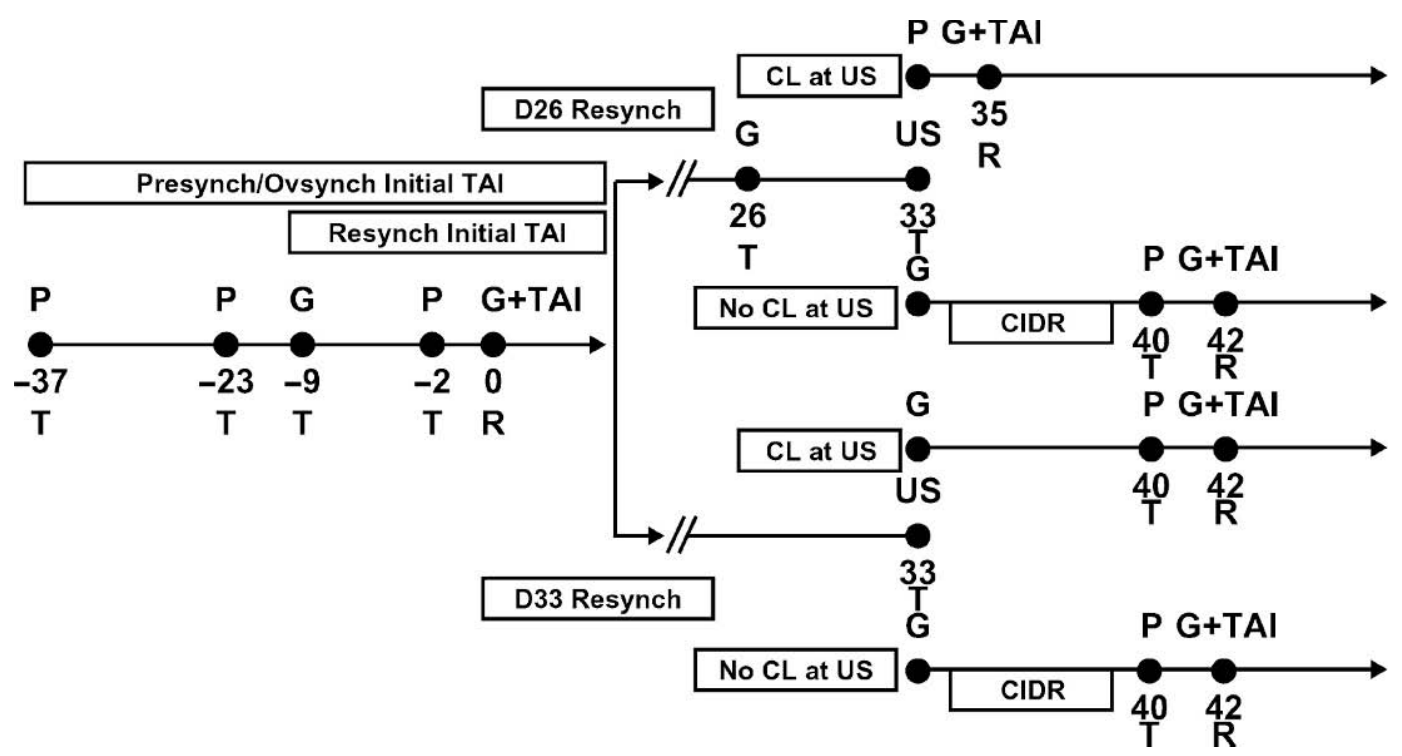

Figure 1. Experimental protocols for cows assigned randomly to the D26 and D33 resynchronization (Resynch) treatments. Cows received an initial timed AI (TAI) after synchronization of ovulation for first postpartum AI using Presynch + Ovsynch (Presynch + Ovsynch Initial TAI) or after resynchronization of ovulation and timed AI using Ovsynch for second or greater TAI (Resynch Initial TAI). After the initial TAI, cows were resynchronized using Ovsynch (Resynch) initiated 26 d (D26 Resynch) or 33 d (D33 Resynch) after the initial TAI. Cows failing to conceive to the initial TAI within each treatment were further classified based on the presence or absence of a corpus luteum (CL) at the not-pregnant diagnosis. Cows without a CL received a CIDR insert (controlled internal drug releasing insert containing $1.38 \mathrm{~g}$ of progesterone) during Resynch. $\mathrm{G}=100 \mu \mathrm{g}$ of $\mathrm{GnRH} ; \mathrm{P}=25 \mathrm{mg}$ of prostaglandin $\mathrm{F}_{2 \alpha} ; \mathrm{R}=$ Thursday; $\mathrm{T}=$ Tuesday; US = not-pregnant diagnosis using transrectal ultrasonography.

Protocols for Resynch treatments are illustrated in Figure 1. All D26 cows $(\mathrm{n}=189)$ received a GnRH injection $26 \mathrm{~d}$ after the previous TAI, and pregnancy status was determined $33 \mathrm{~d}$ after TAI. Nonpregnant cows in the $\mathrm{D} 26$ treatment with a $\mathrm{CL} \geq 10 \mathrm{~mm}$ in diameter $(\mathrm{n}=161)$ received $\mathrm{PGF}_{2 \alpha}$ and a second $\mathrm{GnRH}$ injection and TAI $35 \mathrm{~d}$ after a previous TAI. All cows diagnosed not pregnant in the D26 treatment without a CL $(\mathrm{n}=28)$ received a $\mathrm{GnRH}$ injection and a new CIDR insert (Eazi-Breed CIDR, Pfizer Animal Health, New York, NY) for $7 \mathrm{~d}$ (D26+CIDR). At $40 \mathrm{~d}$ after the initial TAI, CIDR inserts were removed and cows received $\mathrm{PGF}_{2 \alpha}$ with $\mathrm{GnRH}$ and TAI $42 \mathrm{~d}$ after the previous TAI. All nonpregnant cows in the D33 treatment with a CL $\geq 10 \mathrm{~mm}(\mathrm{n}=150)$ received the first $\mathrm{GnRH}$ injection of Resynch $33 \mathrm{~d}$ after the initial TAI, and $\mathrm{PGF}_{2 \alpha} 40 \mathrm{~d}$ and a second GnRH injection and TAI $42 \mathrm{~d}$ after a previous TAI. All nonpregnant cows in the D33 treatment without a $\mathrm{CL} \geq 10 \mathrm{~mm}$ in diameter $(\mathrm{n}=30)$ received Resynch similar to D33 cows with a CL, but with the inclusion of a CIDR insert between the first GnRH injection and the $\mathrm{PGF}_{2 \alpha}$ injection of Resynch (D33+CIDR).

\section{PR/AI and Pregnancy Loss}

Pregnancy examinations and hormone injections were conducted by the herd veterinarian and herd per- sonnel immediately after milking while cows were restrained in a palpation rail located in the return alley leaving the milking parlor. Visualization of a CL, a fluid-filled uterine horn, and presence of a conceptus were used as positive indicators of pregnancy 33, 40, and $61 \mathrm{~d}$ after TAI using an ultrasound machine as described previously (Fricke et al., 1998). Pregnancy rate per AI was defined as the number of cows diagnosed pregnant to TAI expressed as a percentage of cows within that treatment group receiving TAI.

Pregnancy loss was assessed for cows that conceived to the previous and the Resynch TAI services throughout the study. Cows diagnosed pregnant were scheduled for a pregnancy recheck using transrectal ultrasonography $40 \mathrm{~d}$ after TAI. Cows diagnosed pregnant at $40 \mathrm{~d}$ were reexamined $61 \mathrm{~d}$ after TAI to determine pregnancy loss. One cow was not available for examination at 33 $\mathrm{d}$ and was diagnosed pregnant $54 \mathrm{~d}$ after initial TAI. Likewise, 6 cows were not examined at $40 \mathrm{~d}$, but were examined between 54 and $61 \mathrm{~d}$ after TAI. Pregnancy results for these 7 cows were included in the statistical analysis as being pregnant at 33 and $40 \mathrm{~d}$. One cow that was diagnosed pregnant at $33 \mathrm{~d}$ was sold before the recheck at $40 \mathrm{~d}$, whereas 2 pregnant cows were sold after $40 \mathrm{~d}$, but before $61 \mathrm{~d}$, and were not included in the analysis of PR/AI at 40 and $61 \mathrm{~d}$, respectively. Pregnancy loss after TAI for cows diagnosed pregnant at 33 
d was calculated for 3 periods: 33 to $40 \mathrm{~d}, 40$ to $61 \mathrm{~d}$, and overall loss from 33 to $61 \mathrm{~d}$ after TAI.

\section{Experimental Design and Statistical Analyses}

This experiment was conducted as a randomized complete block design (Morris, 1999). Each week at the initial TAI, cows within a weekly breeding group (45.1 \pm 2 cows/group; range $=33$ to 61 cows/group) were blocked according to parity (primiparous vs. multiparous). Within each block, cows were assigned randomly to each of 2 treatments to initiate Resynch at either 26 or $33 \mathrm{~d}$ after initial TAI.

Dichotomous data were analyzed using procedure LOGISTIC of SAS (SAS Institute Inc., Cary, NC). A multivariate logistic regression model was developed to analyze the effects of the categorical variables: treatment (D26 vs. D33), parity (primiparous vs. multiparous), previous synchronization protocol (Presynch + Ovsynch vs. Resynch), and all 2-way interactions of the explanatory variables with treatment on PR/AI and pregnancy loss after AI. The effect of AI sire was not included in either model; however, sires were distributed evenly among treatments.

Initially, data were combined for cows with and without a CL within each treatment to compare these optimized strategies for systematically managing reproduction. Subsequently, comparisons were made for D26 cows with a CL compared with D33 cows with a CL; D26 cows without a CL vs. D33 cows without a CL; D26 cows with a CL vs. D26 cows without a CL; and D33 cows with a CL vs. D33 cows without a CL. All multivariate logistic regression models were constructed using a backward selection process (Agresti, 1996). The effect of treatment was forced to remain in the model during the backward selection process for analysis of Resynch TAI. A Wald statistic criterion of $P<0.15$ was selected for retaining a variable in the statistical model. Odds ratios and $95 \%$ confidence intervals were calculated for all main effects remaining in the final models. Data are presented as percentages and proportions with $P$ values for main effects and interactions derived from the multivariate logistic regression analysis.

\section{RESULTS AND DISCUSSION}

\section{Pregnancy Outcomes and Pregnancy Loss after Previous Al}

Characteristics of and reproductive outcomes for cows receiving AI preceding the Resynch TAI treatments are presented in Table 1. Differences in PR/AI among treatment protocols for the initial TAI must be interpreted carefully because synchronization protocol (Presynch + Ovsynch vs. Resynch) is confounded with insemination number (first postpartum TAI vs. second and greater postpartum TAI) and DIM, and because certain subgroups of cows are represented by few observations.

Reassessment of pregnancy status 40 and $61 \mathrm{~d}$ after the previous TAI allowed for evaluation of pregnancy loss during this period with the objective of determining the optimal intervals after TAI to initially determine and reconfirm pregnancy status during Resynch. In the present study, the pregnancy loss of $3.7 \%$ (13/349) from 33 to $40 \mathrm{~d}, 3.0 \%$ (10/334) from 40 to $61 \mathrm{~d}$, and the overall loss of $6.6 \%$ (23/347) from 33 to $61 \mathrm{~d}$ after TAI was less than the $12.6 \%$ loss from 31 to $45 \mathrm{~d}$ (Chebel et al., 2004 ) and 12 to $16 \%$ loss between 30 to $68 \mathrm{~d}$ reported previously (Fricke et al., 2003; Gümen et al., 2003; Lopez et al., 2004). Vasconcelos et al. (1997) reported pregnancy losses of $11 \%$ from 28 to $42 \mathrm{~d}, 6 \%$ from 42 to 56 $\mathrm{d}$, and $2 \%$ from 56 to $98 \mathrm{~d}$, indicating that the risk of pregnancy loss decreased as gestation progressed.

Pregnancy loss from 33 to $40 \mathrm{~d}$ is of particular interest in this study because 2 timings for identification of nonpregnant cows could be used during the D33 Resynch strategy. For the first option, which was used in the current experiment, pregnancy diagnosis was conducted $33 \mathrm{~d}$ after TAI using transrectal ultrasonography and the first GnRH injection of Resynch was administered only to nonpregnant cows. This first option restricts administration of $\mathrm{GnRH}$ to cows diagnosed not pregnant at $33 \mathrm{~d}$ after TAI, but results in a greater risk for subsequent pregnancy loss for cows diagnosed pregnant at $33 \mathrm{~d}$ after TAI because pregnancy is diagnosed earlier and subject to embryonic losses. A second option would be to administer GnRH to all cows $33 \mathrm{~d}$ after TAI, and identify nonpregnant cows either by transrectal ultrasonography or palpation per rectum (Paisley et al., 1978) at $40 \mathrm{~d}$, with administration of $\mathrm{PGF}_{2 \alpha}$ to nonpregnant cows at the time of the not-pregnant diagnosis. This second option requires that the first GnRH injection of Resynch be administered to all cows regardless of pregnancy status; however, the later pregnancy diagnosis at $40 \mathrm{~d}$ after TAI allows for more nonpregnant cows to be submitted for resynchronization at this time because the additional $7 \mathrm{~d}$ of pregnancy loss (from 33 to $40 \mathrm{~d}$ ) is allowed to occur before establishing pregnancy status. Data regarding pregnancy loss after TAI in this study will be useful for modeling the economics of the timing of not-pregnant diagnosis during Resynch.

\section{Submission of Cows for Resynchronization Treatments}

Of the 763 cows submitted for pregnancy diagnosis $33 \mathrm{~d}$ after the previous TAI, 413 cows were diagnosed 
Table 2. Recorded outcomes for cows diagnosed not pregnant after the AI previous to Resynch timed AI treatments that did not receive a Resynch timed AI service

\begin{tabular}{lccc}
\hline & \multicolumn{2}{c}{ Treatment } & \\
\cline { 2 - 4 } Outcome & $\begin{array}{l}\mathrm{d} 26 \\
\mathrm{n}=207)\end{array}$ & $\begin{array}{l}\mathrm{d} 33 \\
(\mathrm{n}=206)\end{array}$ & $\begin{array}{l}\text { Overall } \\
(\mathrm{n}=413)\end{array}$ \\
\hline & $\mathrm{n}(\%)$ & $\mathrm{n}(\%)$ & $\mathrm{n}(\%)$ \\
Died & $1(0.5)$ & $0(0.0)$ & $1(0.2)$ \\
Sold & $2(1.0)$ & $2(1.0)$ & $4(1.0)$ \\
AI to a detected estrus & $1(0.5)$ & $5(2.4)$ & $6(1.4)$ \\
Not inseminated at scheduled timed AI & $1(0.5)$ & $7(3.4)$ & $8(1.9)$ \\
Marked as "Do Not Breed" & $7(3.4)$ & $3(1.4)$ & $10(2.4)$ \\
Missed or improper injection sequence & $6(2.9)$ & $9(4.4)$ & $15(3.6)$ \\
Total & $18(8.7)$ & $26(12.6)$ & $44(10.7)$ \\
\hline
\end{tabular}

not pregnant and 369 of those cows received a Resynch TAI. Recorded outcomes for cows diagnosed not pregnant after the initial TAI that did not receive a Resynch TAI are shown in Table 2. Reported synchronization protocol compliance for this farm throughout the study is noteworthy, with less than $6 \%$ of cows reported to have missed or received an improper injection sequence or having failed to be inseminated at scheduled TAI (Table 2). Furthermore, the extent to which this farm relied on systematic synchronization and resynchronization of ovulation and TAI for managing reproduction is illustrated by the observation that less than $2 \%$ of cows received $\mathrm{AI}$ to a detected estrus (Table 2).

The proportion of cows with a CL at the not-pregnant diagnosis and their subsequent fertility is shown in Table 3. A similar proportion of D26 cows had a CL
(85.2\%) compared with D33 cows (83.3\%) at the notpregnant diagnosis. The proportion of cows with a CL $33 \mathrm{~d}$ after TAI in the D26 treatment of this study was greater than the proportion of cows with a CL reported by Fricke et al. (2003), in which $68 \%$ of D26 cows had a CL at the first GnRH injection of Resynch. In the present study, however, the not-pregnant diagnosis was conducted $7 \mathrm{~d}$ after $\mathrm{GnRH}$ treatment of the D26 strategy to initiate Resynch; thus, GnRH treatment or the additional time for the CL to develop increased the proportion of cows with a $\mathrm{CL}>10 \mathrm{~mm}$ in diameter using ultrasonography at $33 \mathrm{~d}$ after the initial TAI.

Overall PR/AI after Resynch between D26 cows with a CL (29.2\%) and D26 cows without a CL (25.0\%) did not differ at $33 \mathrm{~d}$ after TAI or at 40 or $61 \mathrm{~d}$ after TAI (Table 3). Although PR/AI did not differ between D26

Table 3. Effect of treatment on the presence or absence of a corpus luteum (CL) at the not-pregnant diagnosis and pregnancy rate per $\mathrm{AI}(\mathrm{PR} / \mathrm{AI})$ after Resynch timed AI

\begin{tabular}{lllll}
\hline \multirow{2}{*}{$\begin{array}{l}\text { Resynch } \\
\text { treatment }\end{array}$} & & \multicolumn{2}{c}{ Not-pregnant diagnosis $^{2}$} & \\
\cline { 3 - 4 } Day 26 & Item & CL + No CIDR & No CL + CIDR & $P$-value \\
& n & 161 & 28 & \\
& \% of cows & 85.2 & 14.8 & \\
& PR/AI (\%) & $29.2(47 / 161)$ & $25.0(7 / 28)$ & 0.651 \\
& 33 d & $27.3(44 / 161)$ & $21.4(6 / 28)$ & 0.515 \\
40 d & $26.7(43 / 161)$ & $21.4(6 / 28)$ & 0.557 \\
61 d & 150 & 30 & \\
& n & 83.3 & 16.7 & 0.305 \\
& \% of cows & $38.0(57 / 150)$ & $46.7(14 / 30)$ & 0.181 \\
& PR/AI (\%) & $35.3(53 / 150)$ & $46.7(14 / 30)$ & 0.125 \\
\hline
\end{tabular}

${ }^{1}$ Cows with a CL at the not-pregnant diagnosis received second or greater timed AI after Ovsynch initiated $26 \mathrm{~d}$ (D26 Resynch) or $33 \mathrm{~d}$ (D33 Resynch) after the initial timed AI. Cows without a CL at the not-pregnant diagnosis were resynchronized using Ovsynch + a CIDR insert $(\mathrm{GnRH}+\mathrm{CIDR}$ insert, $\mathrm{d}$ 0; PGF $2 \alpha+$ CIDR removal, d 7; GnRH + TAI, d 9). All D26 cows without a CL at the not-pregnant diagnosis had received a $\mathrm{GnRH}$ injection $7 \mathrm{~d}$ before pregnancy diagnosis $26 \mathrm{~d}$ after the initial timed AI and received the first GnRH injection of Resynch + CIDR insert $7 \mathrm{~d}$ later at the not-pregnant diagnosis (d 0). All D33 cows received the first GnRH injection of Resynch + a CIDR insert $33 \mathrm{~d}$ after TAI at the not-pregnant diagnosis (d 0).

${ }^{2}$ Cows were classified as having a CL at the not-pregnant diagnosis conducted $33 \mathrm{~d}$ after the initial timed AI when CL diameter was estimated to be $\geq 10 \mathrm{~mm}$. 
Table 4. Effect of 2 strategies for systematic resynchronization of ovulation using Ovsynch initiated 26 d (Day 26 Resynch) or 33 d (Day 33 Resynch) after an initial timed AI with treatment of cows without a corpus luteum (CL) at the not-pregnant diagnosis with progesterone on pregnancy rate per $\mathrm{AI}(\mathrm{PR} / \mathrm{AI})$ and pregnancy loss in lactating cows

\begin{tabular}{|c|c|c|c|c|c|c|c|}
\hline \multirow[b]{3}{*}{ Item } & \multicolumn{4}{|c|}{ Treatment $^{1}$} & & & \\
\hline & \multicolumn{2}{|c|}{ D26 Resynch } & \multicolumn{2}{|c|}{ D33 Resynch } & \multicolumn{3}{|c|}{$P$-value } \\
\hline & Primiparous & Multiparous & Primiparous & Multiparous & Treatment & Parity & Interaction \\
\hline \multicolumn{8}{|l|}{ PR/AI, \% } \\
\hline $33 \mathrm{~d}$ & $31.1(28 / 90)$ & $26.3(26 / 99)$ & $46.9(46 / 98)$ & $30.5(25 / 82)$ & 0.039 & 0.033 & - \\
\hline $40 \mathrm{~d}$ & $28.9(26 / 90)$ & $24.2(24 / 99)$ & $44.9(44 / 98)$ & $28.0(23 / 82)$ & 0.038 & 0.029 & - \\
\hline $61 \mathrm{~d}$ & $27.8(25 / 90)$ & $24.2(24 / 99)$ & $42.9(42 / 98)$ & $27.2(22 / 81)$ & 0.057 & 0.050 & - \\
\hline 40 to $61 \mathrm{~d}$ & $3.8(1 / 26)$ & $0.0(0 / 24)$ & $4.5(2 / 44)$ & $0.0(0 / 22)$ & 0.731 & - & - \\
\hline 33 to $61 \mathrm{~d}$ & $10.7(3 / 28)$ & $7.7(2 / 26)$ & $8.7(4 / 46)$ & $8.3(2 / 24)$ & 0.894 & - & - \\
\hline
\end{tabular}

${ }^{1}$ Cows with a CL at the not-pregnant diagnosis received second or greater timed AI after Ovsynch initiated $26 \mathrm{~d}$ (D26 Resynch) or $33 \mathrm{~d}$ (D33 Resynch) after the initial timed AI. Cows without a CL at the not-pregnant diagnosis were resynchronized using Ovsynch + a CIDR insert $\left(\mathrm{GnRH}+\mathrm{CIDR}\right.$ insert, $\mathrm{d}$ 0; $\mathrm{PGF}_{2 \alpha}+\mathrm{CIDR}$ removal, d 7; GnRH + TAI, d 9). All D26 cows without a CL at the not-pregnant diagnosis had received a GnRH injection $7 \mathrm{~d}$ before pregnancy diagnosis $26 \mathrm{~d}$ after the initial timed AI and received the first GnRH injection of Resynch + a CIDR insert $7 \mathrm{~d}$ later at the not-pregnant diagnosis (d 0). All D33 cows received the first GnRH injection of Resynch + a CIDR insert $33 \mathrm{~d}$ after TAI at the not-pregnant diagnosis ( $\mathrm{d} 0$ ).

${ }^{2}$ Effects with unreported $P$-values were removed from the initial statistical model during the backward selection process of the logistic regression procedure of SAS (SAS Institute, 1999).

cows with and without a CL, treating cows without a $\mathrm{CL}$ at their scheduled $\mathrm{PGF}_{2 \alpha}$ injection with $\mathrm{GnRH}$ and a CIDR insert to reinitiate Resynch, which also delayed insemination from 35 to $42 \mathrm{~d}$ after the initial TAI, may have improved PR/AI. In a previous study conducted on this dairy, cows without a CL at the $\mathrm{PGF}_{2 \alpha}$ injection of Resynch had a PR/AI of only 10\% (Fricke et al., 2003). Similarly, fertility did not differ between D33 cows with a CL at the first GnRH injection of Resynch and those without a CL $(P=0.305 ; 38.0$ vs. $46.7 \% \mathrm{PR} / \mathrm{AI}) 33 \mathrm{~d}$ after TAI or $40 \mathrm{~d}$ after TAI $(P=0.181)$. At $61 \mathrm{~d}$ after TAI there was a tendency $(P=0.125)$ for D33 cows without a CL and treated with a CIDR insert to have a greater PR/AI (46.7\%) than D33 cows with a CL (33.6\%).

\section{Overall Fertility of the D26 vs. D33 Resynch Strategies}

Percentage and proportion of cows diagnosed pregnant to the D26 and D33 Resynch strategies are shown in Table 4. Because no difference was detected between cows with and without a CL within each treatment, data were combined to compare PR/AI of all cows assigned to Resynch treatments. Combining data for cows with and without a CL within treatment allowed for an evaluation of the D26 and D33 Resynch protocols including alternative treatments for cows without a CL at not-pregnant diagnosis. Overall, the D33 Resynch strategy resulted in a greater $(P<0.05) \mathrm{PR} / \mathrm{AI}(39.4 \%)$ at $33 \mathrm{~d}$ after TAI than the D26 Resynch strategy [28.6\%; adjusted odds ratio $(\mathbf{A O R})=1.7 ; 95 \% \mathrm{CI}=1.0$ to 2.5$]$. Similarly, PR/AI was greater $(P<0.05 ; \mathrm{AOR}=1.6 ; 95 \%$
$\mathrm{CI}=1.0$ to 2.5$)$ for the D33 compared with the D26 Resynch strategy at $40 \mathrm{~d}$ after TAI, and tended $(P=$ $0.057)$ to be greater at $61 \mathrm{~d}$ after TAI. Parity influenced PR/AI, with primiparous cows being 1.6 times more ( $P$ $<0.05)$ likely to conceive than multiparous cows $33 \mathrm{~d}$ after TAI (AOR $=1.6 ; 95 \% \mathrm{CI}=1.0$ to 2.5). Primiparous cows also had a greater $(P<0.05) \mathrm{PR} / \mathrm{AI}$ at $40 \mathrm{~d}(\mathrm{AOR}=$ $1.6 ; 95 \% \mathrm{CI}=1.1$ to 2.7$)$ and $61 \mathrm{~d}(\mathrm{AOR}=1.7 ; 95 \% \mathrm{CI}=$ 1.0 to 2.5) after TAI. In contrast, pregnancy loss did not differ between treatments and was not affected by parity or TAI service number possibly because of limited numbers of cows having pregnancy loss within each classification. Overall rate of pregnancy loss after the Resynch TAI was $6.4 \%$ for 33 to $40 \mathrm{~d}, 2.6 \%$ from 40 to $61 \mathrm{~d}$, and $8.9 \%$ from 33 to $61 \mathrm{~d}$.

In a previous study investigating the same intervals from initial TAI to initiation of Resynch, PR/AI was $38 \%$ at $33 \mathrm{~d}$ after TAI for the D33 treatment, with a PR/AI of 34\% $26 \mathrm{~d}$ after TAI for the D26 treatment (Fricke et al., 2003). The PR/AI resulting from these treatments could not be directly compared in that study because of the confounding of time after Resynch TAI to the not-pregnant diagnosis and hence, the amount of pregnancy loss between treatments in this study. In contrast, pregnancy diagnosis for both treatments in the present study was conducted at $33 \mathrm{~d}$ after the initial TAI to allow direct comparison between the 2 treatments. The greater PR/AI for the D33 Resynch strategy in this study confirmed our hypothesis that delaying initiation of Resynch until $33 \mathrm{~d}$ after initial TAI resulted in greater pregnancy rate than initiation of Resynch at $26 \mathrm{~d}$. 
Table 5. Effect of resynchronization of ovulation using Ovsynch initiated at 26 d (Day 26 Resynch) or 33 d (Day 33 Resynch) after an initial timed AI on pregnancy rate per AI (PR/AI) and pregnancy loss for lactating cows with a corpus luteum (CL) at the not-pregnant diagnosis ${ }^{1}$

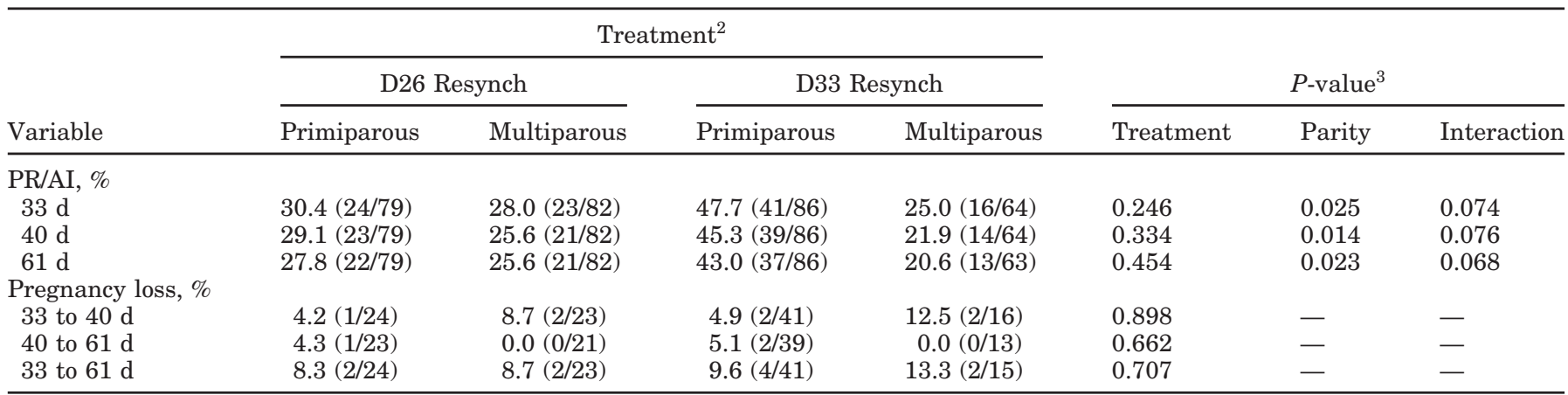

${ }^{1}$ Cows were classified as having a CL at the not-pregnant diagnosis conducted $33 \mathrm{~d}$ after the initial timed AI when CL diameter was estimated to be $\geq 10 \mathrm{~mm}$.

${ }^{2}$ Cows received their second or greater timed AI after resynchronization using Ovsynch (GnRH, d 0; PGF $2 \alpha, d$ 7; GnRH + TAI, d 9) initiated 26 d (D26 Resynch) or 33 d (D33 Resynch) after an initial timed AI (TAI).

${ }^{3}$ Effects with unreported $P$-values were removed from the initial statistical model during the backward selection process of the logistic regression procedure of SAS (1999).

We initially speculated that cows receiving the D33 treatment would be more likely to be at d 5 to 12 of the estrous cycle if luteal regression and ovulation in response to the synchronization protocol were synchronized, a stage of the estrous cycle shown to result in greater fertility when Ovsynch is initiated (Vasconcelos et al., 1999; Moreira et al., 2000; El-Zarkouny et al., 2004). Average interval from initial TAI to estrus can be as long as $23 \mathrm{~d}$ (Pursley et al., 1993; Lopez et al., 2004 a), with up to $22 \%$ of cows expressing estrus $25 \mathrm{~d}$ after TAI (Bartolome et al., 2005). Assuming the interestrus interval ranged from 18 to $24 \mathrm{~d}$, we hypothesized that most D26 cows were in metestrus, whereas most D33 cows were in diestrus at the first GnRH injection. This reasoning supports our hypothesis that a D33 Resynch strategy schedules the first GnRH of Resynch at a more desirable stage of the estrous cycle, and should result in more pregnancies than a D26 Resynch.

\section{Fertility after Resynch for Cows with a CL at the Not-Pregnant Diagnosis}

Reproductive outcomes expressed as percentages and proportions for cows with a CL at the not-pregnant diagnosis are shown in Table 5. Although initiation of Resynch $33 \mathrm{~d}$ after the previous TAI did not affect PR/ AI, primiparous cows were 1.7 times more likely $(P<$ $0.05)$ to conceive than multiparous cows $(\mathrm{AOR}=1.7$; $95 \% \mathrm{CI}=1.0$ to 2.7$)$ at $33 \mathrm{~d}$ after TAI. Primiparous cows had greater $(P<0.05) \mathrm{PR} / \mathrm{AI}$ than multiparous cows at $40 \mathrm{~d}(\mathrm{AOR}=1.9 ; 95 \% \mathrm{CI}=1.1$ to 2.9$)$ and 61 $\mathrm{d}(P<0.05 ; \mathrm{AOR}=1.8 ; 95 \% \mathrm{CI}=1.0$ to 2.9$)$ after TAI. Interestingly, a tendency $(P=0.074)$ for a treatment $\times$ parity interaction was detected for PR/AI at $33 \mathrm{~d}$ after Resynch TAI, with primiparous cows initiating Resynch
$33 \mathrm{~d}$ after initial TAI having greater PR/AI than multiparous cows initiating Resynch at 26 or $33 \mathrm{~d}$ and primiparous cows initiating Resynch $26 \mathrm{~d}$ after initial TAI. Primiparous cows in the D33 treatment tended to have a greater PR/AI at $40(P=0.076)$ and $61 \mathrm{~d}(P=0.068)$ after TAI than multiparous cows in the D26 or D33 Resynch treatments and primiparous cows receiving the D26 treatment. Finally, pregnancy loss did not differ between Resynch treatments and was not affected by parity or TAI service number. Interestingly, pregnancy loss from 33 to $61 \mathrm{~d}$ after Resynch TAI (9.7\%) was numerically greater than that observed for losses after the previous TAI (6.6\%) during this same period. A larger study with more observations from cows having pregnancy loss would be required to confirm whether the rate of pregnancy loss differs based on TAI number or synchronization protocol. Although Ovsynch has been speculated to be a cause of embryonic loss in lactating dairy cows, embryonic loss from 31 to $45( \pm 3) \mathrm{d}$ after AI was similar for cows inseminated after removed tail chalk than for cows receiving TAI after Ovsynch (10.4 vs. $13.2 \%$; Chebel et al., 2004).

Our data agree with other reports in which primiparous cows had a greater PR/AI than multiparous cows (Stevenson et al., 2003; Chebel et al., 2004; Tenhagen et al., 2004; Portaluppi and Stevenson, 2005). Others (Galvão et al., 2004; Navanukraw et al., 2004), however, failed to observe an effect of lactation number on PR/ AI. Reasons for a difference in fertility among cows of different parities are not clearly defined, but primiparous cows produce less total and peak milk, but have greater lactational persistency than multiparous cows (Lean et al., 1989). Furthermore, higher producing dairy cows may have greater negative energy balance and be predisposed to more metabolic and reproductive 
Table 6. Effect of resynchronization of ovulation using Ovsynch initiated $26 \mathrm{~d}$ (Day 26 Resynch) or $33 \mathrm{~d}$ (Day 33 Resynch) after the initial timed AI on pregnancy rate per AI (PR/AI) and pregnancy loss for lactating cows without a corpus luteum (CL) at the not-pregnant diagnosis ${ }^{1}$

\begin{tabular}{|c|c|c|c|c|c|c|c|}
\hline \multirow[b]{3}{*}{ Variable } & \multicolumn{4}{|c|}{ Treatment ${ }^{2}$} & & & \\
\hline & \multicolumn{2}{|c|}{ D26 Resynch } & \multicolumn{2}{|c|}{ D33 Resynch } & \multicolumn{3}{|c|}{$P$-value ${ }^{3}$} \\
\hline & Primiparous & Multiparous & Primiparous & Multiparous & Treatment & Parity & Interaction \\
\hline \multicolumn{8}{|l|}{ PR/AI, \% } \\
\hline $33 \mathrm{~d}$ & $36.4(4 / 11)$ & $17.6(3 / 17)$ & $41.7(5 / 12)$ & $50.5(9 / 18)$ & 0.090 & - & - \\
\hline $40 \mathrm{~d}$ & $27.3(3 / 11)$ & $17.6(3 / 17)$ & $41.7(5 / 12)$ & $50.5(9 / 18)$ & 0.048 & - & - \\
\hline $61 \mathrm{~d}$ & $27.3(3 / 11)$ & $17.6(3 / 17)$ & $41.7(5 / 12)$ & $50.5(9 / 18)$ & 0.048 & - & - \\
\hline \multicolumn{8}{|c|}{ Pregnancy loss, \% } \\
\hline 40 to $61 \mathrm{~d}$ & $0.0(0 / 3)$ & $0.0(0 / 3)$ & $0.0(0 / 5)$ & $0.0(0 / 9)$ & - & - & - \\
\hline 33 to $61 \mathrm{~d}$ & $25.0(1 / 4)$ & $0.0(0 / 3)$ & $0.0(0 / 5)$ & $0.0(0 / 9)$ & 0.951 & - & - \\
\hline
\end{tabular}

${ }^{1}$ Cows were classified as lacking a CL at the not-pregnant diagnosis conducted $33 \mathrm{~d}$ after the initial timed AI when a CL was not visualized on either ovary or when CL diameter was estimated to be $<10 \mathrm{~mm}$.

${ }^{2}$ Cows without a CL at the not-pregnant diagnosis were resynchronized using Ovsynch + a CIDR insert $(\mathrm{GnRH}+\mathrm{CIDR}$ insert, $\mathrm{d}$ 0; PGF $\alpha$ + CIDR removal, d 7; GnRH + TAI, d 9). All D26 cows without a CL at the not-pregnant diagnosis received a GnRH injection before pregnancy diagnosis $26 \mathrm{~d}$ after the initial timed AI and the first GnRH injection of Resynch + a CIDR insert $7 \mathrm{~d}$ later at the not-pregnant diagnosis (d 0). All D33 cows received the first GnRH injection of Resynch + a CIDR insert $33 \mathrm{~d}$ after TAI (d 0).

${ }^{3}$ Effects with unreported $P$-values were removed from the initial statistical model during the backward selection process of the logistic regression procedure.

disorders than lesser producing cows. An increased incidence of reproductive disease reduces fertility (Grohn and Rajala-Schultz, 2000). Although treatment $\times$ parity interactions are not common, Santos et al. (2004) reported an interaction in which primiparous cows treated with bST had greater fertility than untreated primiparous cows, whereas bST treatment had no effect on the reproductive outcomes of multiparous cows. Perhaps the greater average milk production of multiparous cows during our study $(43.8 \pm 0.7$ vs. $36.8 \pm 0.5$ $\mathrm{kg} / \mathrm{d}$ for primiparous cows) altered circulating progesterone and estradiol concentrations (Lopez et al., 2005) and thus follicular dynamics, which resulted in more variation in follicular growth and development for multiparous cows. In addition, multiparous cows have more pregnancy loss than primiparous cows from 33 to $61 \mathrm{~d}$ after TAI. Although we did not evaluate pregnancy loss before $33 \mathrm{~d}$ after TAI, it is possible that multiparous cows may have had more pregnancy loss before $33 \mathrm{~d}$ after TAI, which may have altered subsequent follicular dynamics and therefore response to the Resynch treatment.

\section{Fertility after Resynch for Cows Without a CL at the Not-Pregnant Diagnosis}

For cows without a CL at the not-pregnant diagnosis, a CIDR insert was administered at the GnRH injection and removed at the $\mathrm{PGF}_{2 \alpha}$ injection of Resynch. Reproductive outcomes for these cows are shown in Table 6 . Inclusion of a CIDR insert in not-pregnant cows without a CL was part of the standard reproductive management procedure at this dairy based on results from an earlier experiment conducted on this farm and on other reports in which cows without a $\mathrm{CL}$ at the first $\mathrm{GnRH}$ injection (Fricke et al., 2003) or at the $\mathrm{PGF}_{2 \alpha}$ injection (Fricke et al., 2003; Chebel et al., 2003; Stevenson and Tiffany, 2004) of Ovsynch tended to have reduced fertility compared with cows with a CL at these times. Although timing of the not-pregnant diagnosis after TAI was standardized in the present study, stage of the Resynch protocol at this examination differed between treatments for cows without a CL. All D26 cows had received an injection of GnRH $7 \mathrm{~d}$ before the not-pregnant diagnosis. Thus, we assumed cows without a CL did not ovulate in response to this $\mathrm{GnRH}$ treatment. Cows in the D33 Resynch treatment had not received any previous treatment, and cows lacking a CL may have been in metestrus, proestrus, or anestrus.

Fertility for D33 + CIDR cows tended $(P=0.09)$ to be greater than that for D26 + CIDR at $33 \mathrm{~d}$ after TAI. Differences were detected $(P<0.05)$ at 40 and $61 \mathrm{~d}$, with D26 + CIDR having less than one third the risk of becoming pregnant as the D33 + CIDR cows (AOR = $0.3 ; 95 \% \mathrm{CI}=0.1$ to 1.0 ). Inclusion of a CIDR insert during Resynch for cows having low progesterone at the first GnRH injection has been reported to improve conception rate in lactating dairy cows (El-Zarkouny et al., 2004), and supported our observation for the D33 + CIDR treatment. The reason for the poor fertility of D26 + CIDR cows is unknown at this time. Administering GnRH at the not-pregnant diagnosis to cows in metestrus $30 \mathrm{~d}$ after TAI and initiating Ovsynch $8 \mathrm{~d}$ later resulted in greater conception rates than using Ovsynch alone (Bartolome et al., 2005), indicating that an additional GnRH injection should not have compro- 
mised fertility. It is important to note that cows were not assigned randomly to receive the D26 + CIDR treatment because only cows lacking a CL at d 33 were assigned. Thus, we must consider that this treatment resulted in an unintentional selection of subfertile cows. Finally, because overall numbers of cows without a CL at the not-pregnant diagnosis was limited, the possibility of Type I or Type II statistical errors must be considered when evaluating these results. Further studies with larger numbers of experimental units per treatment are warranted to adequately compare conception rates of lactating dairy cows based on the presence or absence of a CL at initiation of Resynch.

\section{CONCLUSIONS}

Delaying the first injection of GnRH for Resynch until $33 \mathrm{~d}$ after initial TAI yielded more pregnancies for all treated cows, and this occurred because of a greater PR/AI for primiparous, but not multiparous cows with a CL at the not-pregnant diagnosis. Treating cows lacking a CL at a not-pregnant diagnosis with a CIDR insert resulted in a PR/AI similar to cows with a CL at notpregnant diagnosis. Although it is desirable to reinseminate cows as soon as possible after pregnancy status is known, and adoption of ultrasound provides an opportunity to conduct such an early diagnosis, programming cows to receive the first GnRH of Resynch $26 \mathrm{~d}$ after the initial TAI resulted in fewer pregnancies in primiparous cows compared with delaying initiation of Resynch by $7 \mathrm{~d}$ to $33 \mathrm{~d}$ after TAI. Initiating Resynch $33 \mathrm{~d}$ after TAI may group primiparous, but not multiparous cows at a stage of the estrous cycle (d 5 to 12) that may explain the greater PR/AI observed when delaying initiation of Resynch in the present study.

\section{ACKNOWLEDGMENTS}

The authors thank Merial, Ltd. (Duluth, GA) for donating Cystorelin and Am Tech Group Inc. (St. Joseph, MO) for donating Prostamate for this experiment. We also thank Miltrim Farms Inc. (Athens, WI) for use of their cows and facilities. This research was supported by Hatch project WIS04995 to P.M.F.

\section{REFERENCES}

Agresti, A. 1996. An introduction to categorical data analysis. 1st ed. John Wiley \& Sons, New York, NY.

Bartolome, J. A., A. Sozzi, J. McHale, P. Melendez, A. C. M. Arteche, F. T. Silvestre, D. Kelbert, K. Swift, L. F. Archbald, and W. W. Thatcher. 2005. Resynchronization of ovulation and timed insemination in lactating dairy cows. II: Assigning protocols according to stages of the estrous cycle, or presence of ovarian cysts or anestrus. Theriogenology 63:1628-1642.

Chebel, R. C., J. E. P. Santos, R. L. A. Cerri, K. N. Galvao, S. O. Juchem, and W. W. Thatcher. 2002. Effect of resynchronization with GnRH on day 21 after artificial insemination on pregnancy rate and pregnancy loss in lactating dairy cows. Theriogenology 60:1389-1399.

Chebel, R. C., J. E. P. Santos, J. P. Reynolds, R. L. A. Cerri, S. O. Juchem, and M. Overton. 2004. Factors affecting conception rate after artificial insemination and pregnancy loss in lactating dairy cows. Anim. Reprod. Sci. 84:239-255.

El-Zarkouny, S. Z., J. A. Cartmill, B. A. Hensley, and J. S. Stevenson. 2004. Pregnancy in dairy cows after synchronized ovulation regimens with or without presynchronization and progesterone. J. Dairy Sci. 87:1024-1037.

Fricke, P. M. 2002. Scanning the future - Ultrasonography as a reproductive management tool for dairy cattle. J. Dairy Sci. 85:1918-1926.

Fricke, P. M., D. Z. Caraviello, K. A. Weigel, and M. L. Welle. 2003. Fertility of dairy cows after resynchronization of ovulation at three intervals following first timed insemination. J. Dairy Sci. 86:3941-3950.

Fricke, P. M., J. N. Guenther, and M. C. Wiltbank. 1998. Efficacy of decreasing the dose of GnRH used in a protocol for synchronization of ovulation and timed AI in lactating dairy cows. Theriogenology 50:1275-1284.

Galvão, K. N., J. E. P. Santos, S. O. Juchem, R. L. A. Cerri, A. C. Coscioni, and M. Villasenor. 2004. Effect of addition of a progesterone intravaginal insert to a timed insemination protocol using estradiol cypionate on ovulation rate, pregnancy rate, and late embryonic loss in lactating dairy cows. J. Anim. Sci. 82:35083517.

Grohn, Y. T., and P. J. Rajala-Schultz. 2000. Epidemiology of reproductive performance in dairy cows. Anim. Reprod. Sci. 6061:605-614.

Gümen, A., J. N. Guenther, and M. C. Wiltbank. 2003. Follicular size and response to Ovsynch versus detection of estrus in anovulatory and ovular lactating dairy cows. J. Dairy Sci. 86:3184-3194.

Lean, I. J., J. C. Galland, and J. L. Scott. 1989. Relationships between fertility, peak milk yields, and lactational persistency in dairy cows. Theriogenology 31:1093-1103.

Lopez, H., F. D. Kanitz, V. R. Moreira, L. D. Satter, and M. C. Wiltbank. 2004a. Reproductive performance of dairy cows fed two concentrations of phosphorus. J. Dairy Sci. 87:146-157.

Lopez, H., D. Z. Caraviello, L. D. Satter, P. M. Fricke, and M. C. Wiltbank. 2005. Relationship between level of milk production and multiple ovulations in lactating dairy cows. J. Dairy Sci. 88:2783-2793.

Lopez, H., L. D. Satter, and M. C. Wiltbank. 2004b. Relationship between level of milk production and estrous behavior of lactating dairy cows. Anim. Reprod. Sci. 81:209-223.

Moreira, F., R. L. de la Sota, T. Diaz, and W. W. Thatcher. 2000. Effect of day of the estrous cycle at the initiation of a timed artificial insemination protocol on reproductive responses in dairy heifers. J. Anim. Sci. 78:1568-1576.

Moreira, F., C. Orlandi, C. A. Risco, R. Mattos, F. Lopes, and W. W. Thatcher. 2001. Effects of presynchronization and bovine somatotropin on pregnancy rates to a timed artificial insemination protocol in lactating dairy cows. J. Dairy Sci. 84:1646-1659.

Morris, T. R. 1999. Experimental design and analysis in animal sciences. CABI Publishing, New York, NY.

Navanukraw, C., D. A. Redmer, L. P. Reynolds, J. D. Kirsch, A. T. Grazul-Bilska, and P. M. Fricke. 2004. A modified presynchronization protocol improves fertility to timed artificial insemination in lactating dairy cows. J. Dairy Sci. 87:1551-1557.

Paisley, L. G., W. D. Mickelsen, and O. L. Frost. 1978. A survey of the incidence of prenatal mortality in cattle following pregnancy diagnosis by rectal palpation. Theriogenology 9:481-491.

Portaluppi, M. A., and J. S. Stevenson. 2005. Pregnancy rates in lactating cows after presynchronization of estrous cycles and variations of the Ovsynch protocol. J. Dairy Sci. 88:914-921.

Pursley, J. R., M. O. Mee, and M. C. Wiltbank. 1995. Synchronization of ovulation in dairy cows using $\mathrm{PGF}_{2 \alpha}$ and $\mathrm{GnRH}$. Theriogenology 44:915-923.

Pursley, J. R., J. S. Stevenson, and J. E. Minton. 1993. Ovarian follicular waves in dairy cows after administration of gonadotropin-releasing hormone at estrus. J. Dairy Sci. 76:2548-2560. 
Santos, J. E. P., S. O. Juchem, R. L. A. Cerri, K. N. Galvao, R. C. Chebel, W. W. Thatcher, C. S. Dei, and C. R. Bilby. 2004. Effect of $\mathrm{bST}$ and reproductive management on reproductive performance of Holstein dairy cows. J. Dairy Sci. 87:868-881.

SAS Institute. 1999. SAS OnlineDoc. Version 8. SAS Institute Inc., Cary, NC.

Stevenson, J. S., J. A. Cartmill, B. A. Hensley, and S. Z. El-Zarkouny. 2003. Conception rates of dairy cows following early not-pregnant diagnosis by ultrasonography and subsequent treatments with shortened Ovsynch protocol. Theriogenology 60:475-483.

Stevenson, J. S., and S. M. Tiffany. 2004. Resynchronizing estrus and ovulation after not-pregnant diagnosis and various ovarian states including cysts. J. Dairy Sci. 87:3658-3664.
Tenhagen, B. A., R. Surholt, M. Wittke, C. Vogel, M. Drillich, and W. Heuwieser. 2004. Use of Ovsynch in dairy herds - Differences between primiparous and multiparous cows. Anim. Reprod. Sci. $81: 1-11$.

Vasconcelos, J. L. M., R. W. Silcox, J. A. Lacerda, J. R. Pursley, and M. C. Wiltbank. 1997. Pregnancy rate, pregnancy loss, and response to heat stress after $\mathrm{AI}$ at 2 different times from ovulation in dairy cows. Biol. Reprod. 56(Suppl 1):140. (Abstr.)

Vasconcelos, J. L. M., R. W. Silcox, G. J. M. Rosa, J. R. Pursley, and M. C. Wiltbank. 1999. Synchronization rate, size of the ovulatory follicle, and pregnancy rate after synchronization of ovulation beginning on different days of the estrous cycle in lactating dairy cows. Theriogenology 52:1067-1078. 